6320

Research Article

Journal of Extension Education (Conference Special)

Vol. 31 No. 3, 2019

DOI:https://doi.org/10.26725/JEE.2019.3.31.6320-6326

\title{
Constraints Faced in the Usage of Contemporary ICT Tools
}

\author{
M. R. Naveen Kumar ${ }^{1}$ and H. Philip ${ }^{2}$
}

\begin{abstract}
The study was conducted in Kanyakumari district of Tamil Nadu during 2018-19 with the objective of understanding constraints faced by rural youth on Information and Communication Technology (ICT) tools usage. Experimental research design was used. Exactly 160 rural youth respondents who are involved in farming were selected using purposive sampling method in a random manner. The ICT tools experimented with the rural youth were Video, Multimedia slides, Whatsapp, Web page and Mobile application. These ICT tools and platforms were selected based on the data collected through pilot survey. The constraints were ranked based on its percentage. The major constraints included, difficulty in understanding the functions of ICT tools followed by lack of location-specific information and insufficient ICT infrastructure facilities.
\end{abstract}

Keywords: ICT tools, youth; constraints; Tamil Nadu

\section{INTRODUCTION}

The present era is the era of Information and Communication Technology (ICT). The process of information dissemination through ICT tools is very cost effective and time saving. The advent of modern ICT tools has cut short the geographical distances between the people. The digitalization of the whole communication process from source to the receiver using ICT tools narrows down the physical barrier among the people throughout the world. ICT helps farmers in several ways such as, farmers' advisory services through online phone based advisory services, internet supporting information-kiosks, web based online agro-advisory services, video conferencing, online agricultural video channels etc.
The ICT has three major roles to playinformative, instructive and influence. The instructive role of ICT is mainly used in administration areas whereas informative and influential roles of ICT were mainly exploited in development programmes. Even though the ICT platform has several advantages, its reach among the rural population in agricultural and rural development context is yet to gain momentum. Hence, the study was conducted with the objective of understanding the constraints faced by rural youth on ICT tools usage.

\section{METHODOLOGY}

The study was conducted in Kanyakumari district of Tamil Nadu during 2018-19. The district was selected purposively

${ }^{1}$ Ph.D.Scholar and ${ }^{2}$ Former Director of Extension Education, TNAU, Coimbatore.

Received : 16-11-2019; Accepted : 28-01-2020 
where, the respondents were selected through random sampling procedure. Kanyakumari district is the only district in Tamil Nadu where Central Government's ARYA (Attracting and Retaining Youth in Agriculture) scheme is in operation and the major livelihood of Kanyakumari is agriculture. The 160 rural youth performing farming have been selected as sample for the study. These rural youth were enlisted under Krishi Vigyan Kendra's ARYA scheme. The general constraints faced by the rural youths in using ICT tools were obtained from all the respondents. As only educated rural youths have been involved in the study, the data collection tool used was well - structured questionnaire. Percentage analysis tool was used to analyze and tabulate the collected data. For this study, the most popular ICT tools viz., Video, Multimedia service, Mobile application, web page and Whatsapp were selected.

\section{FINDINGS AND DISCUSSION}

Table 1 presents the constraints in the usage of ICT tools by the rural youth respondents.

'Difficulty to understand the functions of ICT tools' was the major constraint expressed by rural youth respondents (95.00 \%) followed by lack of location-specific information (91.25 $\%$ ) and insufficient ICT infrastructure facilities (86.87\%)

The understanding of several functions of ICT tools such as texting, attachment,

Table 1.

Constraints in the Utilization of ICT tools by Rural Youth respondents

\begin{tabular}{|c|c|c|c|c|}
\hline $\begin{array}{l}\text { Sl. } \\
\text { No. }\end{array}$ & Constraints & Frequency & Percentage* & Rank \\
\hline 1. & Difficult to understand the functions of ICT tools & 152 & 95.00 & I \\
\hline 2. & Lack of location specific information & 146 & 91.25 & II \\
\hline 3. & Insufficient ICT infrastructure & 139 & 86.87 & III \\
\hline 4. & Lack of network connectivity & 137 & 85.62 & IV \\
\hline 5. & $\begin{array}{l}\text { Lack of credibility of the information obtained } \\
\text { through ICT tools }\end{array}$ & 131 & 81.87 & \multirow{2}{*}{$\mathrm{V}$} \\
\hline 6. & High price of ICT tools & 131 & 81.87 & \\
\hline 7. & Language barrier & 129 & 80.62 & $\mathrm{VI}$ \\
\hline 8. & Insufficient training on use of ICT tools & 118 & 73.75 & VII \\
\hline 9. & Compatiblility issues & 113 & 70.62 & VIII \\
\hline 10. & Deviation from core purpose & 98 & 61.25 & IX \\
\hline 11. & $\begin{array}{l}\text { Wrong perception that only rich people could buy } \\
\text { and use ICT tools }\end{array}$ & 87 & 54.37 & $x$ \\
\hline
\end{tabular}


upload, share, download and saving the files, etc. was found difficult by the rural youth respondents. Even though all the rural youth respondents used the ICT tools in their day-to-day life only very few of them had understood its functionality. As social media being the open access platform in which a huge amount of information got circulated every second, the tracing of location specific information is little bit difficult. In the present scenario, the ICT infrastructure facilities in the rural India have not been developed well as that of urban area and this might also be the reason for the constraints as reported. Further the ICT services such as browsing centres and common service centres are not available in most of the under developed villages.

The above mentioned findings are in agreement with the findings of Mwakaje (2010) who reported that the lack of knowledge of respondents on how to use the ICT tools and lack of location specific information and insufficient ICT infrastructure facilities as major constraints in ICT tools usage.

\section{Constraints in the Utilization of Multimedia Slides}

The constraints in the utilization of multimedia slides are summarized in Table 2. A close observation of the table reveals that majority $(85.00 \%)$ of the rural youth respondents expressed that they experienced difficulty to operate the Microsoft PowerPoint tool. About 77.50 per cent of them experienced the compatible issues i.e. the fonts, animations and graphics files used in the multimedia slides did not support well in their own computer. This finding is supported by the findings of Devaraja (2011) who said that, complex nature of the few ICT tools affects its utility among the farmers. The above said constraint inferred the lack of knowledge of the rural youth respondents on the operation of Microsoft PowerPoint. Formal classroom setup was cited as a constraint by 55.00 per cent of the rural youth respondents followed by 45.00 per cent of the rural youth respondents felt that it was difficult to follow the hyperlinks. It is observed that the use of

Table 2.

Constraints in the Utilization of Multimedia Slides

\begin{tabular}{|l|l|l|l|l|}
\hline $\begin{array}{r}\text { SI. } \\
\text { No. }\end{array}$ & \multicolumn{1}{|c|}{ Constraints } & \multicolumn{1}{c|}{ Number } & \multicolumn{1}{|c|}{ Percentage* } & \multicolumn{1}{c|}{ Rank } \\
\hline 1. & Difficult to operate Microsoft PowerPoint & 136 & 85.00 & I \\
\hline 2. & Lack of possession of desktop or laptop & 44 & 27.50 & VI \\
\hline 3. & Compatibility issues & 124 & 77.50 & II \\
\hline 4. & Difficult to read the contents & 52 & 32.50 & V \\
\hline 5. & Formal classroom setup & 88 & 55.00 & III \\
\hline 6. & Difficult to follow the hyperlinks & 18 & 45.00 & IV \\
\hline
\end{tabular}

*Multiple responses obtained 
Table 3.

Constraints in the Utilization of Whatsapp

\begin{tabular}{|l|l|c|c|c|}
\hline $\begin{array}{c}|c| \\
\text { SI. } \\
\text { No. }\end{array}$ & \multicolumn{1}{|c|}{ Constraints } & Number & Percentage* & Rank \\
\hline 1. & Difficult to read the contents through the screen & 112 & 70.00 & II \\
\hline 2. & Poor internet connectivity & 80 & 50.00 & III \\
\hline 3. & Lot of distraction & 144 & 90.00 & I \\
\hline 4. & Operational difficulties & 28 & 17.50 & IV \\
\hline
\end{tabular}

${ }^{*}$ Multiple responses obtained

multimedia slides may increase the knowledge of the rural youth respondents. However, in order to harness the potential of multimedia slides, rigorous training is needed for the rural youth respondents.

\section{Constraints in the Utilization of Whatsapp}

The constraints in the utilization of Whatsapp are summarized in Table 3. It could be seen from Table 3 that majority $(90.00 \%)$ of the rural youth respondents expressed that lot of distractions occurs during the Whatsapp reading due to the notification pop-ups of several mobile applications installed in the smartphones which distract them to a greater extent in reading the lengthy texts. Kumar and Sharma (2017) reported in their study that, 29.00 per cent of Whatsapp users perceive distraction while using it. A little more than two-thirds (70.00\%) of the rural youth respondents reported difficulty in reading the contents through the smaller mobile screens and the reason might be that the eye irritation caused due to focused reading. Half of the rural youth respondents $(50.00 \%)$ felt that connecting to the internet was tedious followed by operational difficulty (17.50\%) of Whatsapp. The reasons might be due to poor internet infrastructural facilities available in the rural areas and need of skill in accessing the Whatsapp.

\section{Constraints in the Utilization of Mobile Apps}

The constraints in the utilization of mobile apps other than Whatsapp are summarized in Table 4. The majority (82.50 \%) of the rural youth respondents experienced difficulty in installation of the mobile app. Inukollu et al. (2014) reported that 44.00 per cent of the consumers would delete the mobile app immediately if it face problems in installation and did not perform as expected. During the installation process, several technical information like agreeing to the terms and conditions of the mobile app were displayed, which is hard to understand by the rural youth respondents might have caused the constraint. Lack of feedback and query clarifications and tedious to connect to the internet was reported as constraints by an almost equal number of rural youth respondents i.e. $\mathbf{7 5 . 0 0}$ 
Table 4.

Constraints in the Utilization of Mobile Apps

\begin{tabular}{|c|l|c|c|c|}
\hline \multicolumn{1}{|c|}{ Constraints } & Number & Percentage* & Rank \\
\hline SI. No. & \multicolumn{1}{|c|}{$(n=160)$} \\
\hline 1. & Difficulty in installation of mobile apps & 132 & 82.50 & I \\
\hline 2. & Compatibility issues & 88 & 55.00 & IV \\
\hline 3. & Lack of exploration of the contents & 84 & 52.50 & V \\
\hline 4. & Difficult to read the contents & 60 & 37.50 & VI \\
\hline 5. & Tedious to connect to the internet & 116 & 72.50 & III \\
\hline 6. & Lack of feedback and query clarifications & 120 & 75.00 & II \\
\hline
\end{tabular}

*Multiple responses obtained

per cent and 72.50 per cent respectively. This finding is in line with the findings of Senthil (2013) who reported that due to lack of knowledge on the disseminated agricultural technologies, the presence of Subject Matter Specialist (SMS) was felt by the respondents. The reasons might be due to the fact that, the mobile app created for the study was a static mobile app i.e. offline mobile app, which does not have any provision for feedback and query clarification.

\section{Constraints in the Utilization of Web page}

The constraints in the utilization of web page are summarized in Table 5. The majority of the rural youth respondents (77.50 \%) felt that connecting to the internet was tedious, followed by 67.50 per cent who

Table 5.

Constraints in the Utilization of Web page

*Multiple responses obtained 
Table 6.

Constraints in the Utilization of Video

\begin{tabular}{|c|l|c|c|c|}
\hline $\begin{array}{r}\text { Sl. } \\
\text { No. }\end{array}$ & \multicolumn{1}{|c|}{ Constraints } & Number & Percentage* & Rank \\
\hline 1. & Compatibility issues & 73 & 45.62 & II \\
\hline 2. & Difficulty in understanding the standard language & 61 & 38.12 & IV \\
\hline 3. & Difficulty in following the contents & 68 & 42.50 & III \\
\hline 4. & Lack of feedback and query clarifications & 119 & 74.37 & I \\
\hline
\end{tabular}

${ }^{*}$ Multiple responses obtained

were of the opinion that typing the web address (URL) was difficult. This finding is in agreement with the findings of Senthil (2013), who found that connecting to the internet in rural areas were difficult and more-than three-fourths of the respondents felt difficulty in remembering and typing the URL address, respectively. Less number of mobile network towers present in the rural region and difficulty in remembering complex URLs might be the reason for the constraints.

\section{Constraints in the Utilization of Video}

The constraints in the utilization of video are summarized in Table 6. Three-fourths (74.37\%) of the rural youth respondents expressed the lack of feedback and query clarification options as major constraint while using video. Non-availability of resource persons to clarify the doubts in the video to the respondents while viewing during leisure time. Almost equal percentage of the rural youth respondents reported the compatibility issues $(45.62 \%)$ and difficulty in following the contents (42.50\%) as constraints in the usage of video. This may be due to that the video files created for the study were in the mp4 format and that might have not supported by the smartphones of the said users. Further, difficulty in following the contents purely depends on the individual rural youth respondents' concentration capacity that requires skill.

\section{CONCLUSION}

The major constraints in ICT tool usage were, difficult to understand the functions of ICT tools, lack of location-specific information and insufficient ICT infrastructure facilities. Those reasons identified for the constraints reported, need to be looked into by the extension practitioners for effective ICT usage.

\section{REFERENCES}

Devaraja, S. C. (2011). A Study on Knowledge and Attitude of Farmers Using ICT tools for Farm Communication. Unpublished MSc (Ag) Thesis, UAS, Bengaluru.

Inukollu, V. N., Keshamoni, D. D., Kang, T., \& Inukollu, M. (2014). Factors influencing quality of mobile apps: Role of mobile app development life cycle. preprint arXiv:1410.4537. 
Kumar \& Sharma, S. (2017). Survey Mwakaje, A. G. (2010). Information and Analysis on the usage and Impact of communication technology for rural Whatsapp Messenger. Global Journal of Enterprise Information System, 8(3), 52-57. farmers market access in Tanzania. Journal of Information Technology Impact, 10(2), 111-128. 